\title{
MUCOADHESIVE BUCCAL DRUG DELIVERY SYSTEMS CONTAINING POLYSACCHARIDES
}

\author{
IRINA M. PELIN and DANA M. SUFLET \\ "Petru Poni” Institute of Macromolecular Chemistry, 41A Grigore Ghica Voda Alley, \\ 700487, Iasi, Romania \\ ×orresponding author: Irina M. Pelin, impelin@icmpp.ro
}

Dedicated to the $100^{\text {th }}$ birth anniversary

of Acad. Cristofor I. Simionescu

\begin{abstract}
The buccal mucosa is an attractive site for drug administration as it allows avoiding the enzymatic degradation of the drug in the gastrointestinal tract and its hepatic metabolism. For buccal administration, different drug delivery systems with controlled mucoadhesion have been developed and some of them are available on the market. Mucoadhesion makes it possible to obtain prolonged, local or systemic drug action, and this process is highly influenced by several factors, among which, the reactivity of macromolecules from the formulations is very important. Polysaccharides are increasingly studied due to their abundance in natural resources, low-cost availability and easy chemical modification, but also due to their biocompatibility, biodegradability and non-toxicity properties.

This review briefly describes the advantages of using the buccal route of drug administration, the influencing factors that are taken into account for obtaining mucoadhesive dosage forms, and the main polysaccharides and their derivatives used for fabrication of buccal drug delivery systems.
\end{abstract}

Keywords: mucoadhesion, buccal drug delivery systems, polysaccharides

\section{INTRODUCTION}

In the pharmaceutical field, major attention is granted to the development of mucoadhesive drug delivery systems, allowing drug administration via the mucosal surfaces from the oral cavity, in order to find an easy, safe and efficient way for drug delivery in the case of some diseases. While bioadhesion refers to the adhesion between two materials from which one is a living organic tissue and the other is a natural or synthetic material, the mucoadhesion implies the adhesion between the material and the mucus layer from a tissue surface. The buccal mucosa is a favorable site for drug absorption and delivery, because it is a stable tissue, having a higher vascularization ensured by a dense capillary-vessel network, and has the advantage of a relatively low enzymatic activity. Using this way of administration, the enzymatic degradation in the gastrointestinal tract and the hepatic metabolism will be avoided.

The buccal mucosa contains three distinctive layers of cells and the first layer has epithelial cells surrounded by mucus, a gel-like secretion of the cells belonging to salivary glands. The viscous mucus layer contains water-insoluble glycoproteins (mucins), immunoglobulins, enzymes, lipids, nucleic acids, cellular debris and ionic species, and all these components have a lower or a higher contribution to the mucoadhesion phenomena. ${ }^{1,2}$

Important advantages of buccal drug delivery systems (BDDS) consist in: - easy application in the oral cavity, which offers comfort to the patient comparatively with other routes of drug administration; - an attractive site for pediatric and aged patients; - better onset of action due to the mucosal contact surface; - lack of side effects, as for example: nausea, vomiting and pain. These features allow drug administration in various pathologies that require local effect (in some oral disorders) or systemic treatments (in systemic diseases). Nevertheless, there are some drawbacks as well, such as: - limitative rate of drug absorption because of different permeability of the buccal mucosa for certain molecules or small absorption area; - instability of some drugs at salivary $\mathrm{pH}$; - unpredictable distribution of the 
drug on the absorption surface; - detachment of the product because of excessive secretion of the salivary glands or because of mechanical stress during eating, drinking and talking. ${ }^{1,3-6}$

Drug administration through the buccal mucosa membrane is recommended for the treatment of chronic inflammatory diseases (oral lichen planus, recurrent aphthous stomatitis, aphthous ulcers or canker sores), chronic oral mucosal pain, oral fungal infections, periodontal diseases, cardiovascular diseases (hypertension), migraine, nausea and vomiting associated with cancer chemotherapy. ${ }^{7}$

BDDS are pharmaceutical devices comprising synthetic or natural components, having one or more functions, as for example: penetration enhancers, permeable or non-permeable layers, residence time, drug reservoir or carrier, which favors the delivery of active pharmaceutical ingredients (API) to a specific local site or into systemic circulation, and sustained mucoadhesion. Most of the polymers that are used in BDDS formulations are mainly hydrophilic, natural or synthetic polymers, which swell and can interact with glycoproteins from the buccal mucosa. In BDDS formulations, the mixture of natural with synthetic polymers is used to ensure not only the mucoadhesive property, but also other important features.

The main features of an ideal BDDS are the following: ${ }^{1,8-10}$

- to adhere quickly to the buccal mucosa;

- to resist at salivary $\mathrm{pH}$;

- to mechanically resist to the action of mastication;

- to have a suitable structure and chemical composition so as to facilitate drug delivery and absorption;

- to provide controlled drug release in a desired period of time;

- to ensure a good acceptance (by masking the bitter taste of the drug and not causing irritation to the patient).

Mucoadhesion is a complex process that involves various types of interactions between the polymers from BDDS and the buccal mucosa, and to explain this phenomenon, some theories have been proposed: ${ }^{11,12}$

- wetting theory: correlates the surface tension of the mucus layer and the charged polymer ability to spread on the buccal mucosa;

- electronic theory: regards the electrostatic attraction between opposite groups of charged surface and adhesive polymer;
- adsorption theory: considers physical and/or chemical interactions between the mucoadhesive polymers and mucins through hydrogen bonds, van der Waals forces and/or covalent bonds;

- diffusion theory: refers to the diffusion of soluble mucins into the BDDS, resulting in the formation of physical entanglement between mucins and flexible polymer chains;

- mechanical theory: refers to the effect of surface roughness on mucoadhesion due to an increased contact area between BDDS surface and mucous buccal membrane;

- fracture theory: relates the difficulty of separating two surfaces after adhesion (the force necessary for polymer detachment from the mucous surface) to the strength of their adhesive bond.

All the factors mentioned above will influence the quality and the quantity of the delivered API from BDDS. Moreover, the environmental factors from the oral cavity, such as saliva, mucus, and the associated forces developed during talking, eating or drinking, will have an important contribution as well.

Saliva maintains the physiological environment of the mouth in a constant balance due to its $\mathrm{pH}$, composition and the volume continuously secreted. Saliva is a complex oral fluid that contains $99.55 \%$ water and only $0.45 \%$ organic (mucins, IgA, enzymes, total proteins, total lipids, amino acids, urea, ammonia) and inorganic constituents $\left(\mathrm{Na}^{+}, \mathrm{K}^{+}, \mathrm{Ca}^{2+}, \mathrm{Mg}^{2+}, \mathrm{Cl}^{-}\right.$, $\mathrm{HCO}_{3}^{-}, \mathrm{PO}_{4}{ }^{3-}, \mathrm{SCN}^{-}, \mathrm{I}^{-}, \mathrm{F}^{-}$). Its presence in the buccal cavity is vital due to its many functions, among which those of a lubricant fluid ensuring protection against mechanical, thermal and chemical irritation; an ionic reservoir that inhibits spontaneous precipitation of calcium, and phosphate salts; a buffer agent, which neutralizes $\mathrm{pH}$ after eating; a cleansing agent for food and aids swallowing; an antimicrobial agent that controls the oral microflora; agglutination action resulting in clearance of bacterial cells; pellicle formation as protective diffusion barrier formed on enamel; participation at first digestion through the most abundant enzyme, $\alpha$-amylase; as solvent facilitating the interaction of foodstuff with taste buds; ensures water balance by increasing drinking necessity when dehydration conditions occur. ${ }^{13}$

The wet surface of the buccal mucosa is ensured by the presence of the mucus layer - a viscoelastic gel containing $95-99 \%$ water, $1-5 \%$ glycoproteins, and a few other components in 
small amounts: enzymes, nucleic acids and mineral salts. ${ }^{8}$ An important contribution in adhesion between the wet mucosal membrane and BDDS is ensured by the glycoproteins (mucins), consisting of protein-based backbones (12-17\%), having around $70 \%$ serine, threonine and proline, and oligosaccharide-based grafted chains $(63 \%)$ made of $\mathrm{N}$-acetylgalactosamine, $\mathrm{N}$ acetylglucosamine, galactose, fucose and $\mathrm{N}$ acetylneuramic acid (sialic acid). ${ }^{11}$ Mucins are negatively charged due to the presence of carboxylate groups (from sialic acid) and ester sulfates at the end of some sugar units ( $\mathrm{pKa}$ of these acidic groups is 1.0-2.6), behaving like anionic polyelectrolytes at neutral $\mathrm{pH}$, with a viscoelastic behavior governed by water content, while lipids and ions from the mucus ensure protection and lubrication. ${ }^{11,14}$

The adhesion force/bond between polymers and the mucous buccal membrane will be dependent on some parameters specific to the macromolecules from BDDS: $:^{8,12,15,16}$

- the molecular weight;

- the macromolecular flexibility;

- the concentration and charged groups density;

- the hydrophilicity/hydrophobicity of the polymer;

- the cross-linking ratios;

- swelling/de-swelling capacity;
- the adhesion and release mechanisms.

Also, some factors relating to buccal tissues ${ }^{4}$ are very important for BDDS mucoadhesion stability:

- the level of moisture of the buccal membrane;

- the composition, $\mathrm{pH}$ and quality and quantity of the saliva;

- the structural integrity and the permeability degree of the mucous surface;

- the masticatory stress.

The benefits of using polysaccharides or polysaccharide derivatives in formulations for BDDS lay the basis for the development of a new generation of pharmaceutical devices. Polysaccharides are complex natural polymers, abundantly present in nature in a variety of structures, with varied properties, making them available in many applications as food and pharmaceutical additives or excipients, as binders, bulking agents, film coatings, sweeteners or suspending agents. Due to their special properties, such as biocompatibility, biodegradability, easiness to transform into various derivatives, they have been intensively used in controlled drug delivery systems.

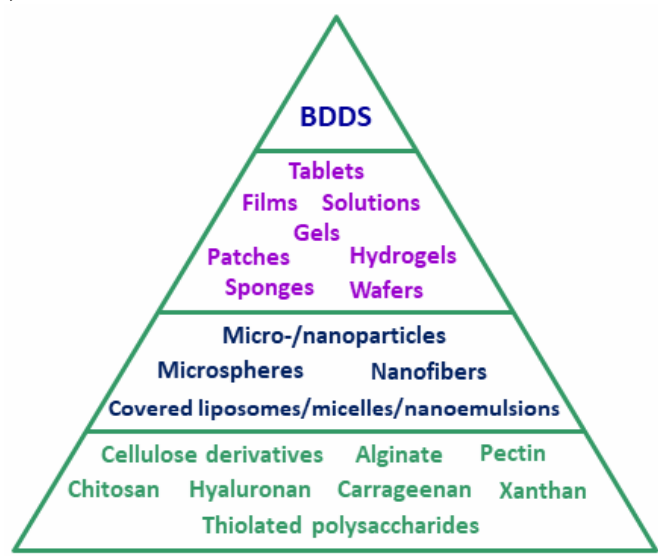

Figure 1: Scheme of BDDS components from macromolecules to final products

To improve mucoadhesivity, they can be subjected to numerous chemical reactions, when useful chemical species can be grafted. For example, polysaccharides bearing thiol groups have been observed to provide much higher mucoadhesivity comparing with the polysaccharides known to be mucoadhesive.
Mucoadhesivity is ensured by the covalent disulfide bonds that are formed between the thiolated polysaccharides and the mucus layer, which contains glycoproteins with cysteine-rich subdomains. ${ }^{9,17-20}$

Figure 1 lists, from bottom to top, the polysaccharides used in BDDS formulations, then 
the various shapes in which they can be obtained at the micro and nanometric scale, and then the dosage forms that include these shapes, all of them being part of BDDS. Natural polymers in various micro-/nanostructures can be regarded as important elements to increase the API encapsulation and bioavailability, to ensure mucoadhesion and at the same time to permeate the buccal membrane, as to favor API delivery in a controlled manner to a maximum efficiency. The API that can be administered via the buccal route include: antimicrobial or hypoglycaemic agents, analgesics, antihypertensive or antiinflammatory drugs, antibiotics, proteins or hormones, and vaccines, which can be delivered to local or in systemic circulation from various mucoadhesive dosage forms: $:^{2-4,7,8,10,12,15,21,22}$

\section{BUCCAL DOSAGE FORMS \\ Tablets}

Buccoadhesive tablets are small and flat discs with a little variation of diameter (around $7 \mathrm{~mm}$ ) that permit the delivery of API during prolonged contact with the buccal mucosa, without causing significant discomfort during speaking, eating or drinking. Tablets were designed to release API either unidirectionally, passing only by the buccal mucosa, or bidirectionally into the saliva and the buccal membrane. The equilibrium between swelling, erosion and diffusion mechanisms will influence the delivery rate of the drug from the polymeric matrix. ${ }^{7,21,23,24}$ Polysaccharides usually used in tablets are: cellulose derivatives, alginate, pectin, xanthan, and chitosan. ${ }^{25}$ The research in this field has materialized in the development of commercial products, as for example, Oravig ${ }^{\circledR}$, Loramyc $^{\circledR}$, Nitrograd ${ }^{\circledR}$, Suboxane ${ }^{\circledR}$, Buccastem ${ }^{\circledR}$ and Striant ${ }^{\circledR}$.

\section{Solutions}

The solutions used as BDDS are commercialized as mouthwash (when solution and suspensions of API are intended to exert local action in the buccal cavity for a short period of time) or as liquid aerosols (when a protective film is formed in contact with the buccal mucosa, which helps to immediately relieve pain and support healing). ${ }^{26}$ When rapid delivery of API is recommended, this type of BDDS is a good alternative as it allows avoiding interference with eating, drinking and talking. Also, for the patients who experience dry mouth, a spray can be a better alternative, since the dissolution of the spray is not dependent upon the patient's saliva. ${ }^{27}$ An ideal mucoadhesive polymer solution suitable for the treatment of oral diseases can be designed as spray, which contains a suitable concentration of polymer, as to adhere to the buccal mucosa, and as a thermosensitive polymer that is liquid at room temperature and semi-solid (gel) at oral cavity temperature $\left(36{ }^{\circ} \mathrm{C}\right) .{ }^{28}$ The polysaccharides used in spray formulations are hyaluronic acid, chitosan and cellulose derivatives. The research in this field has materialized in commercial products, such as URGO Filmogel ${ }^{\circledR}$, Mouth Ulcers, Gum Aftamed ${ }^{\circledR}$ Mouth Spray, Aloclair $^{\circledR}$ PLUS oral spray solution, Oralin ${ }^{\circledR}$, RapidMist $^{\mathrm{TM}}$.

\section{Films/patches}

Unidirectional or multidirectional drug release through the buccal mucosa can be achieved using films due to their soft, flexible and adhesive features, which improve the comfort feeling of patients. ${ }^{29-36}$ Buccal patches present the same advantages as films, with the difference that they are manufactured as laminates, comprising two or more layers, usually three: an impermeable backing layer, a drug-containing layer that controls the release of API, and a mucoadhesive layer that will be in contact with the mucosal surface. ${ }^{7,21,37-44}$ Sometimes, in the scientific literature, the term 'buccal patch' is used to refer to the mucoadhesive film. ${ }^{45-50}$ The polysaccharides usually used in film/patch formulations include cellulose derivatives, alginate, pectin, xanthan, carrageenan, hyaluronan, chitosan and thiolated polysaccharides. The research in this field has led to the development of commercial products, such as Onsolis ${ }^{\circledR}$, Setofilm ${ }^{\circledR}$, Triaminic ${ }^{\circledR}$, and buccal patches: OraMoist ${ }^{\circledR}$, Dentipatch ${ }^{\circledR}$.

\section{Gels}

Gels are usually clear and transparent semisolid BDDS, containing solubilized drugs. They have been widely used in the delivery of drugs in the oral cavity since the formulations can be easily dispersed onto the mucosal membrane. Their high water content reduces irritancy and can release API quickly at the absorption site. ${ }^{51,52}$ To improve the retention of these types of formulations, mucoadhesive polysaccharides, as for example, sodium carboxymethylcellulose, hyaluronic acid, or xanthan gum, were added to modify viscosity and to control the release of drugs. ${ }^{4,7}$ Commercial gels are on the market, as for example: Gengigel ${ }^{\circledR}$, Aftex Forte Oral Gel. 


\section{Hydrogels}

Hydrogels are 3D structures and can have different shapes and pore sizes, and due to their hydrophilic character, they are able to adsorb water and expand their form while maintaining their structural integrity due to the cross-linking degree. ${ }^{53}$ The composition, morphology (gels, micro-/nanoparticles, cross-linked matrices) and physicochemical properties of hydrogels will influence chain relaxation and interaction with other chemical compounds, making them able to load different hydrophilic API, to protect the drug from the action of some external factors, to react at some stimulus in order to release the drug, and to form adequately interchain bridges with components of the biological medium. ${ }^{2,22,54-58}$ The most frequently used polysaccharides for obtaining hydrogels include alginate, pectin, hyaluronan, xanthan gum, carrageenan, chitosan. The research in this field has materialized in the following commercial products: URGO Filmogel $^{\circledR}$ Mouth Ulcers, Tantum verde ${ }^{\circledR}$ SOS afte.

\section{Sponges}

Sponges facilitate sustained drug release for a long period of time due to their swollen structure. Sponges have highly porous structures resulting not only from the method of preparation, but also from the lyophilization techniques applied. By freeze drying, the incorporated water is removed, so that a porous or non-porous, soft solid structure with adequate flexibility is obtained and the release of the drug can be controlled. ${ }^{59-64}$

\section{Wafers}

Basically, the main features of wafers as BDDS are the same as those for buccal films/patches, hydrogels or sponges: flexibility, elasticity, softness, mucoadhesivity, with a difference in their benefits consisting in: low residual moisture and increased drug loading (for low solubility drugs), protection against mechanical removal, and their ability to maintain their swollen structure for a long time, hence improving drug absorption. ${ }^{65-71}$ Polysaccharides used in wafer formulations are: alginate, pectin, xanthan, carrageenan, cellulose derivatives, chitosan and thiolated polysaccharides. Commercial wafers are available on the market, as for example, Wafermine ${ }^{\mathrm{TM}}$, Wafesil $^{\mathrm{TM}}$.

The dosage forms mentioned above can also be hybrid materials, containing micro-/nano particles, microspheres, nanofibres obtained from polysaccharides, or colloidal systems that are covered by a polysaccharide layer that will protect the drug carrier and will enhance the permeability of the buccal mucosa.

\section{Micro-/nanoparticles}

Micro-/nanoparticles can be obtained by different methods or techniques, such as wet precipitation, ionic complexation, ionotropic gelation, oil-in-water emulsion-solvent evaporation, spray-drying, and can be used in BDDS applications as spray-dried particles, aqueous suspensions, or incorporated into a gel matrix or film. Mucoadhesive polysaccharidebased micro-/nanoparticles loaded with API present some advantages: protection of the drug from the oral $\mathrm{pH}$ and enzymatic degradation, protection from the action of the saliva, enhancing solubility of the poorly soluble drugs, and release of drugs towards the buccal mucosa in a controlled manner. ${ }^{6,42,72,73}$ Polysaccharide-based nanoparticles obtained especially from chitosan, alginate, xanthan gum, and cellulose derivatives have been investigated and the results have shown that they can be successfully used as components in BDDS. ${ }^{74-77}$

\section{Microspheres}

Microspheres can be prepared by different techniques (solvent evaporation, single or doubleemulsion, spray drying technique, to name a few) and by variations of the fabrication parameters, the control of particle size and size distribution being thus achieved. Microspheres made from polysaccharides (chitosan, alginate) are biocompatible, can encapsulate many types of drugs ensuring high bioavailability of API and their release for long periods of time. ${ }^{78-80}$ Another advantage of applying API loaded microspheres in BDDS is their release by means of aerosols. In this way, the microspheres can be positioned straight onto the mucosal surface and an intimate contact with a larger mucosal surface will be achieved. ${ }^{81}$

\section{Nanofibers}

Nanofibres are obtained by the electrospinning technique from a polymer solution or melt, and their features will depend on the applied voltage, concentration of the polymer, flow rate adjustment, needle-to-collection distance and environmental parameters. Nanofibre meshes could be impregnated with API and can be used in BDDS as component in buccal patches, which, 
together with mucoadhesive polysaccharides (chitosan, alginate, pectin) or cellulose derivatives, will allow adhesion to the moist oral mucosa, and the release of the drug will be controlled by the rate of diffusion or degradation of the nanofibers. ${ }^{82-85}$

\section{Liposomes, micelles, nanoemulsions}

Colloidal systems, such as liposomes, micelles, micro-/nanoemulsions, can be used as BDDS in different forms, such as mouthwashes, oral sprays or incorporated in gels or films. ${ }^{86-88}$ These micro-/nanostructures are intensively studied for API encapsulation and delivery due to their ability to increase drug loading and bioavailability, to enhance drug solubility and release, to enhance protection against chemical or enzymatic degradation, to reduce drug toxicity, and to control mucoadhesion performance or time stability, when suitable polysaccharides or polysaccharide derivatives are used as a coating layer surrounding the liposomes or micellar structures. ${ }^{89,90}$ Liposomal buccal mucoadhesive films containing vitamin B6, hydroxypropylmethylcellulose and carboxymethylcellulose have been characterized and the main results, such as the slow release, high stability, and enhanced permeability through a model membrane, were found encouraging for the development of a new BDDS. ${ }^{91}$

\section{POLYSACCHARIDES POLYSACCHARIDE DERIVATIVES}

AND

Neutral or ionic polysaccharides are intensively exploited in the field of drug delivery systems because they can react with various chemical compounds. They can be used as such or can be transformed (following various reactions as: etherification, esterification, oxidation, reductive amination, imine formation, formation of quaternary ammonium salts, acylation) ${ }^{92}$ into highly stable, safe, non-toxic, water-soluble derivatives, having additional important features for the interaction with biological tissues or fluids, as for example: mucoadhesivity, biocompatibility, low immunogenicity and biodegradability. ${ }^{93}$

Cellulose derivatives (especially, cellulose ethers) are modified polysaccharides frequently used in pharmaceutical formulations due to their physicochemical properties: solubility, limited crystallinity, hydrogen bonding capability, high glass transition temperatures, high chemical and photochemical stability, and low toxicity (no ability to permeate through gastrointestinal cells) and can be easily obtained from cellulose, the most abundant biopolymer and sustainable raw material on Earth. ${ }^{94,95}$ Even if the non-ionic polymers are less adhesive than both anionic and cationic polymers, their adhesion to the buccal mucosa is ensured by the entanglement of the polymeric chains that could be formed after the penetration of the macromolecules through the mucous membrane. ${ }^{11,96}$

Hydroxyethylcellulose (HEC) is a non-ionic derivative, obtained through etherification of alkali cellulose with ethylene oxide. ${ }^{97}$ HEC is soluble both in cold and hot water. It has a high degree of substitution, solubility and viscosity, and good heat stability (below $140{ }^{\circ} \mathrm{C}$ ). HEC is a biocompatible, biodegradable, non-toxic, hydrophilic, non-ionic water soluble derivative of cellulose and by grafting it with other polymers/compounds, it acquired applications in controlled drug release as carrier. ${ }^{97}$ HEC can be used as agent in topical drug formulations to facilitate the delivery of hydrophobic drugs,${ }^{98}$ but also in the composition of BDDS as gel formulation containing piroxicam. ${ }^{99}$ HECcysteamine nanoparticles with free thiol groups were generated via ionic gelation, and were evaluated in terms of mucoadhesivity, permeation enhancement, biocompatibility and biodegradability, and the results showed that this derivative could be a promising excipient for nanoparticle delivery systems for poorly absorbed drugs. ${ }^{100}$

Hydroxypropylcellulose (HPC) is a non-ionic cellulose derivative obtained by etherification of cellulose with propylene oxide under alkaline conditions. ${ }^{95}$ HPC is soluble in cold and hot water, and in some polar solvents, forming a transparent viscous solution with a nonNewtonian flow behavior. HPC is used in formulations to modify the viscosity and to stabilize colloids and emulsions. In oral and topical pharmaceutical products, it is used as binder to increase the stability of tablets and as film former. ${ }^{95,101-103}$

Hydroxypropylmethylcellulose (HPMC), also named hypromellose, is a water-soluble and electro-neutral cellulose derivative obtained following the addition of methyl and hydroxypropyl groups to the cellulose backbone..$^{95}$ HPMC contains no less than $16.5 \%$ and no more than $30 \%$ methoxyl groups, and no less than $4 \%$ and no more than $32 \%$ hydroxypropyl residues. ${ }^{104}$ It is used to form swellable soluble matrices, 
being one of the most common hydrophilic cellulose derivatives used in the drug release matrix systems. ${ }^{105-107}$ HPMC influences the release of a drug in a controlled manner, increasing the duration of drug release to prolong its therapeutic effect, and can be used alone or in combination with hydrophilic or hydrophobic, non-ionic or ionic polymers. ${ }^{108}$ Besides their usefulness in traditional oral drug formulations, HPMC and its derivatives are intensively exploited in modern pharmaceutical technologies (like spray drying, hot-melt extrusion, 3D printing, nanoprecipitation and electrospinning), which allow obtaining nanoparticles, microparticles, and nanofiber-based delivery systems for oral and oromucosal applications. ${ }^{108}$ HPMC possesses a large number of hydroxyl groups that allow interactions with the mucin glycoproteins present in the mucus layer and, for this reason, it has a relevant potential for use in different mucoadhesive drug delivery formulations. In mucoadhesive BDDS, HPMC is usually used in combination with other polymers. $^{42,91,109-111}$

Carboxymethylcellulose (CMC) is a methylcellulose with the methyl group substituted with a carboxyl group through an alkali-catalyzed reaction of cellulose with chloroacetic acid. ${ }^{112}$ It is similar in appearance to most cellulose derivatives, and it has different water solubility as a function of the degree of substitution. CMC solutions have good viscosity stability over the pH 4 to 10 range, and are compatible with most water soluble non-ionic gums, being suitable for oral formulations. ${ }^{113} \mathrm{CMC}$ is available in high purity forms and can be used in the manufacture of drug delivery systems, such as film coating tablets, gels, emulsions and nanoparticles. ${ }^{114}$ It is an anionic polymer able to form hydrogen bonds or electrostatic interactions when it comes in contact with other ionic/non-ionic polysaccharides. CMC seems to have good mucoadhesive properties. In BDDS formulations, it is usually used in combination with non-ionic or ionic polysaccharides to enhance the mucoadhesive effect. It was observed that in formulations containing at least two polysaccharides or polysaccharide derivatives, the drug release can be improved. For example, it was observed that gels containing cellulose derivative polymers (CMC, HPC, HPMC) interact with mucins from the mucus gel layer, increasing the residence time on the mucosa and the association CMC and HPC in the weight ratio $2 / 3$ better sustains the release of chlorhexidine from the gel and can be proposed as a formulation for daily disinfection of the oral cavity. ${ }^{115}$ To improve delivery and permeation of water-soluble vitamins, vitamin B6 was entrapped in liposomes, which were included into a mucoadhesive film composed of sodium CMC and HPMC. ${ }^{91}$ A CMC derivative was obtained by thiolation with cysteine via amid bond formation, and the thioCMC showed promising mucoadhesiveness, compared with the unmodifed one, which recommends it for BDDS formulations. ${ }^{116}$

Alginates are extracted from marine brown algae, but can also be obtained from some bacteria through microbial fermentation. ${ }^{117}$ This polysaccharide is a linear block copolymer composed of 1,4-linked $\beta$-D-mannuronic acid with ${ }^{4} \mathrm{C}_{1}$ ring conformation and $\alpha$-L-guluronic acid with ${ }^{1} \mathrm{C}_{4}$ conformation, both in the pyranosic conformation and present in varying amounts. ${ }^{118}$ An important physical property of alginate is that it is selective for binding multivalent cations and favoring gel formation, and that the sol/gel transition is not influenced by temperature. ${ }^{117}$ The conventional use of alginate in pharmaceutical products is as excipient with thickening, gelforming, and stabilizing properties. Also, the mucoadhesive property of alginate makes it suitable as delivery vehicle for drugs through mucosal surfaces, improving drug effectiveness and bioavailability. ${ }^{39,119,120}$ Alginate microspheres as nystatin carriers for oral candidiasis have been developed and the physicochemical properties, antifungal activity, in vitro release behavior and in vivo absorption have shown that a gel containing microspheres can prolong the action of the drug by increasing the contact and residence time of this BDDS on the mucus membrane. ${ }^{121}$ To improve the mucoadhesive properties of alginate, 1-cysteine was covalently linked to the polymer and the results showed that the thiolated alginate is useful as excipient for various drug delivery systems, providing improved stability and prolonged residence time on certain mucosal epithelia. $^{122}$

Pectins are water-soluble polysaccharides present in the cell walls of most plants. They are anionic polysaccharides consisting of partially esterified $\alpha-(1-4)-D$-galacturonic acid residues, forming a homogalacturonan backbone. ${ }^{123}$ The complexity of pectins arises from their heterogeneous composition (content of Lrhamnose residues and branched chains composed 
of neutral sugars, such as galactose or arabinose) and degrees of esterification, which depend on the age of the source and on the presence of enzymes that impede or determine random distribution of free carboxylic groups. ${ }^{118}$ Some factors, such as $\mathrm{pH}$, molecular size, degree of methoxylation, charge density on the molecule number, and arrangement of side chains, influence the gelation of pectin. In the pharmaceutical industry, it is used in the fabrication of edible films, in products for decreasing blood cholesterol levels and in some gastrointestinal disorders. ${ }^{124}$ Moreover, it is used as an encapsulating agent for the sustained drug release alone or in combination with gelatin or alginate. ${ }^{124}$ It has been demonstrated that pectin binds to mucin and forms interpenetrating gel networks. ${ }^{125}$ Pectin with a low degree of esterification has a significant mucoadhesion, while branched or heterogeneous backbone structures reduce its adhesive properties. ${ }^{125}$ By changing the molecular characteristics of pectin, it is possible to adjust the interaction of pectin with mucin in order to satisfy specific requirements of drug delivery. ${ }^{126}$ Furthermore, it was shown that low-ester pectin is more mucoadhesive than amidated and high-ester pectin, despite having a lower molecular weight. ${ }^{127}$ To improve the mucoadhesiveness of pectin, it was reacted using thioglycolic acid, and thiolated pectin showed higher mucoadhesivity, compared with the unmodified pectin, due to the presence of disulfide bonds formed between mucus and thiolated pectin. ${ }^{128}$

Hyaluronan, also known as hyaluronic acid (HA), is an anionic polysaccharide consisting of repeating disaccharide units of $\mathrm{N}$-acetyl glucosamine and glucuronic acid linked by $\beta-1,3$ and $\beta-1,4$ glycosidic bonds. It is a glycosaminoglycan, which is distributed widely throughout connective, epithelial and neural tissues. ${ }^{12}$ The unique viscoelastic nature of hyaluronan, and its biocompatibility and nonimmunogenicity makes it suitable for applications in cosmetic, medical, and pharmaceutical products. ${ }^{129}$ It was observed that a decrease in the molecular weight of HA enhances the mucoadhesive performance, for example the HA with a molecular weight of $202 \mathrm{kDa}$ shows potential applications in buccal delivery of acyclovir. ${ }^{130}$ The mucoadhesive effect of HA can be ensured either by its ability to interact with mucin via hydrogen bonds and electronic interactions, or by interpenetration and physical interlocking with mucin chains, the second one being the most probable mechanism involved in the mucoadhesive behavior of this polysaccharide. ${ }^{131}$ A novel biocomposite made of vitamin B12-loaded nanofibers and a blend of HA and polyvinyl alcohol was developed for sublingual delivery of nicorandil in an attempt to reduce mucosal ulceration and to improve drug bioavailability. ${ }^{83}$ Compared with the unmodified hyaluronan, the thiolated hyaluronic acid improved the mucoadhesivity and the permeationenhancing effect of the hyaluronan-based formulation, being a promising candidate for the development of novel BDDS. ${ }^{132,133}$

Xanthan gum is a high molecular weight polysaccharide produced by aerobic fermentation of sugars by the bacterium Xanthomonas campestris. The primary structure of xanthan gum contains repeated polysaccharide units containing two d-glucopyranosyl units, two dmannopyranosyl units and one glucopyranosyluronic acid unit. ${ }^{134}$ Xanthan gum is an anionic, water-soluble polymer, stable in a wide range of $\mathrm{pH}$ and temperature values, and can be used as gelling agent, wetting agent and stabilizer in emulsions or dispersions. It is commonly utilized in pharmaceutical, cosmetic and food products. ${ }^{135}$ Xanthan gum was investigated as drug release modifier, as well as mucoadhesive polymer in order to obtain buccal patches, and the results showed that this polysaccharide has good bioadhesion and can change the drug release rate, but a penetration enhancer is necessary to achieve maximum permeation of the drug through the buccal mucosa. ${ }^{136}$ Also, xanthan derivatives were obtained by modifying the xanthan with thiol groups, and the improved swelling features, mucoadhesive strength, and stability of the obtained formulations demonstrated the benefits of using xanthan in BDDS. ${ }^{137-139}$

Carrageenan is a linear sulfated polysaccharide that is extracted from red seaweeds (Rhodophyceae) and it is composed of galactose and anhydrogalactose units, linked by glycosidic unions. ${ }^{140}$ Carrageenan is a generic name for a family of high molecular polysaccharides, from which kappa (К-), iota (l-) and lambda $\left(\lambda_{-}\right)$carrageenans are the names for those containing one, two or three sulfate groups per unit of disaccharide. ${ }^{140}$ Due to the special characteristics of carrageenans, such as strong negative charge, gelling and viscosity properties, they have been used as gelling agent/viscosity 
enhancing agent for controlled drug release. In pharmaceutical products, carrageenan is used as a polymer matrix in oral extended-release tablets, as a novel extrusion agent for the production of pellets and as a carrier/stabilizer in micro/nanoparticle systems. ${ }^{141}$

The k-carrageenan has the ability to form hydrogen bonds and dative bonds between the sulfate groups and the $\mathrm{NH}_{2}$ groups of mucin from the buccal mucosa. ${ }^{2}$ In formulations designed as BDDS, it was observed that wafers prepared by lyophilization of gels containing carrageenan and/or natural or synthetic polymers possess optimum swelling and mucoadhesion. ${ }^{66,71,142,143}$ Thiolated carrageenans exhibit mucoadhesive properties and this could be useful in improving the efficacy of carrageenan as antitumor and antiviral agent. ${ }^{144}$

Chitosan is the most versatile cationic polysaccharide intensively used in BDDS formulations. It is a $(1 \rightarrow 4) 2$-amino-2-deoxy- $\beta$-Dglucan, obtained by the alkaline deacetylation of chitin. It is considered a copolymer of $\mathrm{N}$ acetylglucosamine and glucosamine, the sugar backbone consisting of $\beta$-1,4-linked glucosamine with a various degree of $\mathrm{N}$-acetylation, a structure very similar to that of cellulose, except that the acetyl amino group replaces the hydroxyl group on the $\mathrm{C}-2$ position. ${ }^{145}$ Chitosan is biocompatible and biodegradable, non-allergenic, and can act as film forming, hydrating agent, absorption promoter, antifungal agent, antibacterial agent, immune adjuvant, anticholesteremic agent, and antithrombogenic agent, which make it suitable for biomedical applications. ${ }^{118}$ As a pharmaceutical excipient, chitosan is used in conventional formulations for tablets, gels, emulsions, films, wafers, but is also used in novel drug delivery systems, such as microspheres, microcapsules, transmucosal drug transport systems, vaccines or DNA delivery systems. ${ }^{34,78,145-147}$ In pharmaceutical products that imply mucoadhesion, chitosan is used due to the cationic groups responsible for the ionic interactions between the cationic primary amino groups and anionic substructures in the form of sialic acid and sulfonic acid from the mucus gel layer. In addition to this, hydrophobic interactions might contribute to its mucoadhesive properties. ${ }^{148}$

Chitosan can influence the opening of the intercellular tight junctions, allowing the paracellular transport of macromolecular drugs across the mucosal epithelium. ${ }^{149-150}$ In comparison with other mucoadhesive polymers, such as Polycarbophil or Carbomer or hyaluronic acid, the mucoadhesive properties of the chitosan are weak, ${ }^{148,152}$ but can be improved by immobilization of thiol groups following chemical modification with sulfhydryl bearing agents. ${ }^{17,19,148,153}$

A drug loaded mucoadhesive buccal film containing: carboxymethyl chitosan as a bioadhesive polymer, glycerol as a plasticizer, and phospholipid-bile salts-mixed micelles as nanoscale carriers, was proved to be an effective carrier for Cucurbitacin B delivery, a potent anticancer agent, which is water-insoluble, causes gastrointestinal side effects and non-specific toxicity via oral administration. ${ }^{87}$ Chitosan was used as adhesive polymer for the preparation of buccal bilayered systems (bilaminated films) for achieving sustained release of either hydrophilic or lipophilic drugs. For this, chitosan was crosslinked with Polycarbophil to control the swelling, drug release and mucoadhesive properties of BDDS, and it was demonstrated that this system is suitable for buccal administration of the antihypertensive drugs, as nifedipine and propranolol hydrochloride. ${ }^{154}$ Buccal patches with various small molecule drugs incorporated have been developed by mixing chitosan with other mucoadhesive polymers, such as alginate, HPMC, CMC, to control API delivery and the mucoadhesive properties. ${ }^{155}$ Laminated chitosanHPMC composite sponges were exploited as solid matrices for buccal delivery of tripterine phytosomes, and the mucoadhesion and the absorption of tripterine via the buccal mucosa was significantly improved. ${ }^{156}$ Lyophilised wafers from chitosan have been developed as potential protein drug delivery systems via the buccal mucosa using bovine serum albumin as a model protein. ${ }^{65}$ A mucoadhesive thermogel, suitable for the treatment of oral mucositis, was developed in order to be proposed as a spray product. The gel contained suitable quantities of mucoadhesive polymer (chitosan, $\mathrm{Na}-\mathrm{CMC}$, polyvinylpyrrolidone, Carbopol 971P NF), which would favor the adhesion to the mucosa, and a thermosensitive polymer (Pluronic F127, Pluronic P123), allowing the formulation to be liquid at room temperature and to become semi-solid (gel) at oral cavity temperature (around $37{ }^{\circ} \mathrm{C}$ ). ${ }^{28}$ Chitosan microspheres were loaded with chlorhexidine (an antimicrobial agent) and included in buccal tablets to give a prolonged release of API in the buccal cavity. ${ }^{78}$ A multiple- 
unit system comprising mucoadhesive bilayer buccal tablets of carvedilol-loaded chitosan microspheres was developed and it was observed that the bioavailability and the therapeutic efficacy of carvedilol were improved. ${ }^{79,157}$

The advances in pharmaceutical technologies have opened new opportunities to design and fabricate mucoadhesive chitosan-based formulations in order to develop new BDDS for a more efficient and less painful way of API administration.

\section{CONCLUSION}

Mucoadhesive BDDS have gained increasing attention for developing new pharmaceutical products due to their many advantages, since the buccal way of administration offers comfort to patients and almost no secondary effects. In this review, BDDS in the form of tablets, sprays, films, patches, gels, hydrogels, sponges and wafers have been briefly described. The main neutral and ionic polysaccharides have been mentioned, considering their importance in mucoadhesion, permeation enhancement and control of drug delivery. The use of natural resources is continuously increasing because the chemical structure and the special properties of the polysaccharides make them suitable to be used in BDDS fabrication.

However, a new type of BDDS, which will address a specific type of drug, a specific disease and the individual particularities of patients, still remains a challenge for the researchers, and new polysaccharide derivatives will be explored.

ACKNOWLEDGEMENTS: This work was supported by a grant of the Romanian Ministry of Research and Innovation, CCDI - UEFISCDI, project number PN-III-P2-2.1-PED-2019-1780, within PNCDI III.

\section{REFERENCES}

1 S. Verma, M. Kaul, A. Rawar and S. Saini, Int. J. Pharm. Sci. Res., 2, 1303 (2011)

2 E. Russo, F. Selmin, S. Baldassari, C. G. M. Gennari, G. Caviglioli et al., J. Drug Deliv. Sci. Technol., $\quad 32, \quad 113 \quad$ (2016), http://dx.doi.org/10.1016/j.jddst.2015.06.016

R. P. Chinna, K. S. C. Chaitanya and R. Y. Madhusudan, DARU J. Pharm. Sci., 19, 385 (2011)

4 S. S. Lokhande and S. S. Lahoti, Asian J. Biomed. Pharm. Sci., 2, 29 (2012)

5 L. I. Giannola, V. De Caro and F. M. Sutera, Ther. Deliv., 5, 965 (2014), https://doi.org/10.4155/tde.14.64
6 A. S. Macedo, P. M. Castro, L. Roque, N. G. Thome, C. P. Reis et al., J. Control. Release, 320, 125 (2020), https://doi.org/10.1016/j.jconrel.2020.01.006

7 R. M. Gilhotra, M. Ikrama, S. Srivastava and N. Gilhotra, J. Biomed. Res., 28, 81 (2014), https://doi.org/10.7555/JBR.27.20120136

8 N. Salamat-Miller, M. Chittchang and T. P. Johnston, Adv. Drug Deliv. Rev., 57, 1666 (2005), https://doi.org/10.1016/j.addr.2005.07.003

9 Y. Sudhakar, K. Kuotsu and A. K. Bandyopadhyay, J. Control. Release, 114, 15 (2006), https://doi.org/10.1016/j.jconrel.2006.04.012

10 S. Punitha and Y. Girish, Int. J. Res. Pharm. Sci., 1, $170(2010)$

11 V. V. Khutoryanskiy, Macromol. Biosci., 11, 748 (2011), https://doi.org/10.1002/mabi.201000388

12 S. Mansuri, P. Kesharwani, K. Jain, R. K. Tekade and N. K. Jain, React. Funct. Polym., 100, 151 (2016), http://dx.doi.org/10.1016/j.reactfunctpolym.2016.01.01

13 H. Whelton, in "Saliva and Oral Health", edited by M. Edgar, C. Dawes and D. O'Mullane, Stephen Hancocks Ltd., 2012, pp. 1-16

14 J. B. da Silva, S. Barbosa de Souza Ferreira, O. de Freitas and M. L. Bruschi, Drug Dev. Ind. Pharm., 43, 1053

(2017),

http://dx.doi.org/10.1080/03639045.2017.1294600

15 F. Fiza, B. Sudhir, R. C. Jat, A. Priyanka, S. Garima et al., Indo Am. J. Pharm. Res., 3, 3324 (2013)

16 J. Liang, X. Peng, X. Zhou, J. Zou and L. Cheng, Molecules, $\quad 25, \quad 516 \quad$ (2020), http://dx.doi.org/10.3390/molecules25030516

17 A. Bernkop-Schnurch, Adv. Drug Deliv. Rev., 57, 1569

(2005),

http://dx.doi.org/10.1016/j.addr.2005.07.002

18 M. Hanif, M. Zaman and S. Qureshi, Int. J. Polym. Sci., 2015, Article ID 146329 (2015), http://dx.doi.org/10.1155/2015/146329

${ }_{19}$ S. Duggan, W. Cummins, O. O' Donovan, H. Hughes and E. Owens, Eur. J. Pharm. Sci., 100, 64 (2017), http://dx.doi.org/10.1016/j.ejps.2017.01.008

20 M. Tekade, N. Maheshwari, S. R. Youngren-Ortiz, V. Pandey, Y. Chourasiya et al., in "Biomaterials and Bionanotechnology”, edited by R. K. Tekade, Elsevier Inc., 2019, pp. 459-493

21 S. Barua, H. Kim, K. Jo, C. W. Seo, T. J. Park et al., Int. J. Pharm. Investig., 46, 593 (2016), http://dx.doi.org/10.1007/s40005-016-0281-9

22 S. J. Morantes, D. M. Buitrago, J. F. Ibla, Y. M. Garcia, G. I. Lafaurie et al., in "Biopolymer-Based Composites, Drug Delivery and Biomedical Applications", edited by S. Jana, S. Maiti and S. Jana, Elsevier Ltd., 2017, pp. 107-138

${ }^{23}$ R. V. Lalla and R.-J. Bensadoun, Expert. Rev. AntiInfect. Ther., $\quad 9, \quad 13 \quad$ (2011), https://doi.org/10.1586/eri.10.152

${ }^{24}$ H. Koradia and K. Chaudhari, J. Drug Deliv. Sci. Technol., 43, $233 \quad$ (2018), http://dx.doi.org/10.1016/j.jddst.2017.10.012 
25 L. L. Fontinele de Sa, N. C. Nogueira, E. C. Da Silva Filho, A. Figueiras, F. Veiga et al., J. Appl. Pharm. Sci., $\quad$ 8, $150 \quad$ (2018), http://dx.doi.org/10.7324/JAPS.2018.8223

26 P. Modi, M. Mihic and A. Lewin, Diabetes Metab. Res. Rev., $\quad \mathbf{1 8 ,} \quad 38 \quad$ (2002), https://doi.org/10.1002/dmrr.208

27 K. Parmar and M. B. Patel, Int. J. Pharm. Sci. Res., 8 , 4533 (2017), http://dx.doi.org/10.13040/IJPSR.0975-8232.8 (11).4533-39

28 C. Pagano, S. Giovagnoli, L. Perioli, M. C. Tiralti and M. Ricci, Eur. J. Pharm. Sci., 142, 105125 (2020), https://doi.org/10.1016/j.ejps.2019.105125

29 A. F. Borges, C. Silva, J. F. J. Coelho and S. Simoes, J. Control. Release, 206, 1 (2015), http://dx.doi.org/10.1016/j.jconrel.2015.03.006

30 S. Karki, H. Kim, S.-J. Na, D. Shin, K. Jo et al., Asian J. Pharm. Sci., 11, 559 (2016), https://doi.org/10.1016/j.ajps.2016.05.004

31 K. P. Garnock-Jones, Clin. Drug Investig., 36, 413 (2016), https://doi.org/10.1007/s40261-016-0394-y

32 M. Montenegro-Nicolini and J. O. Morales, AAPS Pharm. Sci. Tech., 18, 3 (2017), https://doi.org/10.1208/s12249-016-0525-z

33 A. Abruzzo, F. P. Nicoletta, F. Dalena, T. Cerchiara, B. Luppia et al., Int. J. Pharm., 531, 257 (2017),

http://dx.doi.org/10.1016/j.ijpharm.2017.08.070

34 R. Kumria, B. E. Al-Dhubiab, J. Shah and A. B. Nair, J. Pharm. Innov., 13, 133 (2018), https://doi.org/10.1007/s12247-018-9312-6

35 C. Zhang, Y. Liu, W. Li, P. Gao, D. Xiang et al., Pharm. Dev. Technol., 24, 118 (2019), https://doi.org/10.1080/10837450.2018.1428814

36 J. F. Alopaeus, M. Hellfritzsch, T. Gutowski, R. Scherließ et al., Eur. J. Pharm. Sci., 142, 105142 (2020), https://doi.org/10.1016/j.ejps.2019.105142

37 R. Anders and H. P. Merkle, Int. J. Pharm., 49, 231 (1989), https://doi.org/10.1016/0378-5173(89)90347-5

38 D. R. Sanvordeker and S.-H. S. Leung, United States Patent, Patent number: 4,900,552, Feb.13, 1990

39 S. N. R. Adhikari, B. S. Nayak, A. K. Nayak and B. Mohanty, AAPS Pharm. Sci. Tech., 11, 1038 (2010), https://doi.org/10.1208/s12249-010-9459-z

40 A. R. Kerr, P. M. Corby, S. S. Shah, M. A. Epler, G. S. Fisch et al., J. Am. Dent. Assoc., 141, 1250 (2010), https://doi.org/10.14219/jada.archive.2010.0053

${ }^{41}$ R. M. Obaidat, A. Bader, W. Al-Rajab, G. Abu Sheikha and A. A. Obaidat, Sci. Pharm., 79, 197 (2011), http://dx.doi.org/10.3797/scipharm.1004-18

42 C. Cavallari, A. Fini and F. Ospitali, Eur. J. Pharm. Biopharm., $\quad 83, \quad 405 \quad$ (2013), https://doi.org/10.1016/j.ejpb.2012.10.004

${ }_{43}$ P. Rana and R. S. R. Murthy, Drug Deliv., 20, 224 (2013), https://doi.org/10.3109/10717544.2013.779331
44 A. R. Shirvan, A. Bashari and N. Hemmatinejad, Eur. Polym. J., 119, $541 \quad$ (2019), https://doi.org/10.1016/j.eurpolymj.2019.07.010

45 L. Perioli, V. Ambrogi, F. Angelici, M. Ricci, S. Giovagnoli et al., J. Control. Release, 99, 73 (2004), https://doi.org/10.1016/j.jconrel.2004.06.005

46 V. M. Patel, B. G. Prajapati and M. M. Patel, Acta Pharm., 57, 61 (2007), https://doi.org/10.2478/v10007007-0005-9

47 S. V. Deshmane, M. A. Channawar, A. V. Chandewar, U. M. Joshi and K. R. Biyani, Int. J. Pharm. Pharm. Sci., 1, 216 (2009)

48 A. Kaur and G. Kaur, Saudi Pharm. J., 20, 21 (2012), https://doi.org/10.1016/j.jsps.2011.04.005

49 S. C. Jagdale, P. Mohanty, A. R. Chabukswar and B. S. Kuchekar, Rev. Cienc. Farm. Basica Apl., 35, 29 (2014)

50 J. Marimutho, N. Varghese, S. K. Jaganadan and D. Sudagar, Int. J. Pharm. Pharm. Sci., 3, 30 (2016)

51 K. P. S. Kumar, D. Bhowmik, A. Dutta, S. Paswan and L. Deb, Crit. Rev. Pharm. Sci., 1, 83 (2012)

52 S. Lefnaoui and N. Moulai-Moste, Colloids Surf. A Physicochem. Eng. Asp., 458, 117 (2014), http://dx.doi.org/10.1016/j.colsurfa.2014.01.007

53 T. Nagai and Y. Machida, Adv. Drug Deliv. Rev., 11, 179 (1993)

54 N. A. Peppas and J. J. Sahlin, Biomaterials, 17, $1553(1996)$

55 J. Xu, S Strandman, J. X. X. Zhu, J Barralet and M Cerruti, Biomaterials, 37, $395 \quad$ (2015), http://dx.doi.org/10.1016/j.biomaterials.2014.10.024

56 F. Alhaique, M. A. Casadei, C. Cencetti, T. Coviello, C. D. Meo et al., J. Drug Deliv. Sci. Technol., $\quad 32, \quad 88 \quad$ (2016), http://dx.doi.org/10.1016/j.jddst.2015.09.018

57 N. A. N. Hanafy, S. Leporatti and M. A. ElKemary, Appl. Sci., 9, $825 \quad$ (2019), https://doi.org/10.3390/app9050825

${ }_{58}$ R. A. Baus, F. Zahir-Jouzdani, S. Dunnhaupt, F. Atyabi and A. Bernkop-Schnurch, Eur. J. Pharm. Biopharm., $\quad$ 142, 498 (2019), https://doi.org/10.1016/j.ejpb.2019.07.019

59 A. Portero, D. Teijeiro-Osorio, M. J. Alonso and C. Remunan-Lopez, Carbohyd. Polym., 68, 617 (2007), http://dx.doi.org/10.1016/j.carbpol.2006.07.028

60 T. Phaechamu and J. Charoenteeraboon, AAPS Pharm. Sci. Tech., 9, 829 (2008), http://dx.doi.org 10.1208/s12249-008-9117-x

61 M. Goldberg, A. Manzi, E. Aydin, G. Singh, P. Khoshkenar et al., J. Nanotechnol. Eng. Med., 5, 040905-1 (2014), http://dx.doi.org/10.1115/1.4030899

62 M. A. A. Kassem, A. N. El Meshad and A. R. Fares, AAPS Pharm. Sci. Tech., 16, 537 (2015), https://doi.org/10.1208/s12249-014-0243-3

${ }^{63}$ H. A. Hazzah, R. M. Farid, M. M. A. Nasra, M. A. El-Massik and O. Y. Abdallah, Int. J. Pharm., 492, 248 (2015), http://dx.doi.org/10.1016/j.ijpharm.2015.06.022 
64 M. S. Freag, W. M. Salehb and O. Y. Abdallah, Eur. J. Pharm. Sci., 120, 10 (2018), https://doi.org/10.1016/j.ejps.2018.04.041

65 I. Ayensu, J. C. Mitchell and J. S. Boateng, Colloids Surf. B Biointerfaces, 91, 258 (2012), https://doi.org/10.1016/j.colsurfb.2011.11.004

66 F. Kianfar, M. Antonijevic, B. Chowdhry and J. S. Boateng, Colloids Surf. B Biointerfaces, 103, 99 (2013), https://doi.org/10.1016/j.colsurfb.2012.10.006

67 J. S. Boateng and I. Ayensu, Drug Dev. Ind. Pharm., $\quad 40, \quad 611 \quad$ (2014), https://doi.org/10.1016/j.ijpharm.2010.01.008

${ }^{68}$ G. M. El-Mahrouk, O. N. El-Gazayerly, A. A. Aboelwafa and M. S. Taha, Int. J. Pharm., 467, 100 (2014), http://dx.doi.org/10.1016/j.ijpharm.2014.03.049

${ }^{69}$ S. S. Timur, S. Yuksel, G. Akca and S. Senel, Int. J. $\quad$ Pharm., $\quad$ 559, $102 \quad$ (2019), https://doi.org/10.1016/j.ijpharm.2019.01.029

70 J. S. R. Costa, K. de Oliveira Cruvinel and L. Oliveira-Nascimento, J. Adv. Res., 20, 33 (2019), https://doi.org/10.1016/j.jare.2019.04.010

71 S. Farias and J. S. Boateng, Int. J. Pharm., 589, 119807 https://doi.org/10.1016/j.ijpharm.2020.119807

72 A. Grenha, M. E. Gomes, M. Rodrigues, V. E. Santo, J. F. Mano et al., J. Biomed. Mater. Res., 92A, 1265 (2010), https://doi.org/10.1002/jbm.a.32466

73 R. C. Feitosa, D. C. Geraldes, V. L. Beraldo-deAraujo, J. S. Ribeiro Costa and L. OliveiraNascimento, Front. Pharmacol., 10, 1 (2019), https://doi.org/10.3389/fphar.2019.01057

74 M. Kilicarslan, M. Gumustas, S. Yildiz and T. Baykara, Curr. Drug Deliv., 11, 98 (2014), https://doi.org/10.2174/15672018113109990055

75 S. Pistone, F. M. Goycoolea, A. Young, G. Smistad and M. Hiorth, Eur. J. Pharm. Sci., 96, 381 (2017), http://dx.doi.org/10.1016/j.ejps.2016.10.012

76 P. Kraisit, S. Limmatvapirat, M. Luangtana-Anan and P. Sriamornsak, Asian J. Pharm. Sci., 13, 34 (2018), https://doi.org/10.1016/j.ajps.2017.07.006

77 J. K. Patra, G. Das, L. F. Fraceto, E. V. Ramos Campos, M. del Pilar Rodriguez-Torres et al., J. Nanobiotechnol., $\quad \mathbf{1 6}, \quad 1 \quad$ (2018), https://doi.org/10.1186/s12951-018-0392-8

78 P. Giunchedi, C. Juliano, E. Gavini, M. Cossu and M. Sorrenti, Eur. J. Pharm. Biopharm., 53, 233 (2002), https://doi.org/10.1016/s0939-6411(01)00237-5

79 P. Yedurkar, M. K. Dhiman, K. Petkar and K. Sawant, J. Microencapsul., 29, 126 (2012), https://doi.org/10.3109/02652048.2011.630109

80 N. T. T. Uyen, Z. A. A. Hamid, N. X. T. Tram and N. Ahmad, Int. J. Biol. Macromol., 153, 1053 (2020), https://doi.org/10.1016/j.ijbiomac.2019.10.233

81 W.-Z. Jiang, Y. Cai and H.-Y. Li, Powder Technol., $\quad 312, \quad 124 \quad$ (2017), http://dx.doi.org/10.1016/j.powtec.2017.02.021
82 T. J. Sill and H. A. von Recum, Biomaterials, 29, 1989

(2008),

https://doi.org/10.1016/j.biomaterials.2008.01.011

83 B. Singh, T. Garg, A. K. Goyal and G. Rath, Artif. Cells Nanomed. Biotechnol., 44, 1498 (2016), https://doi.org/10.3109/21691401.2015.1052472

84 G. L. Perez-Gonzalez, L. J. Villarreal-Gomez, A. Serrano-Medina, E. J. Torres-Martinez and J. M. Cornejo-Bravo, Int. J. Nanomed., 14, 5271 (2019), https://doi.org/10.2147/IJN.S193328

85 J. G. Edmans, K. H. Clitherow, C. Murdoch, P. V. Hatton, S. G. Spain et al., Pharmaceutics, 12, 504 (2020),

https://doi.org/10.3390/pharmaceutics 12060504

86 P. Modi, M. Mihic and A. Lewin, Diabetes Metab. Res. Rev., $\quad \mathbf{1 8}, \quad$ S38 (2002), https://doi.org/10.1002/dmrr.208

87 Q. Lv, C. Shen, X. Li, B. Shen, C. Yu et al., Drug Deliv., $\quad 22, \quad 351 \quad$ (2015), https://doi.org/10.3109/10717544.2013.876459

${ }_{88}$ T. A. Ahmed, A. O. Bawazir, W. S. Alharbi and M. K. Safo, Int. J. Nanomed., 15, 4001 (2020), https://doi.org/10.2147/IJN.S256925

89 J. K. Bangia and H. Om, Int. J. Pharm. Sci. Res., 6, 1363 (2015), https://doi.org/10.13040/IJPSR.09758232.6(4).1363-72

90 A. Gavin, J. T. H. Pham, D. Wang, B. Brownlow and T. A. Elbayoumi, Int. J. Nanomed., 10, 1569 (2015), https://doi.org/10.2147/IJN.S75474

91 H. A. El Azim, N. Nafee, A. Ramadan and N. Khalafallah, Int. J. Pharm., 488, 78 (2015), https://doi.org/10.1016/j.ijpharm.2015.04.052

92 I. Cumpstey, ISRN Org. Chem., 2013, Article ID 417672 (2013), http://dx.doi.org/10.1155/2013/417672 93 B. Layek and S. Mandal, Carbohyd. Polym., 230, 115617

(2020), https://doi.org/10.1016/j.carbpol.2019.115617

94 D. Klemm, B. Heublein, H.-P. Fink and A. Bohn, Angew. Chem. Int. Ed., 44, 3358 (2005), https://doi.org/10.1002/anie.200460587

95 H. C. Arca, L. I. Mosquera-Giraldo, V. Bi, D. Xu, L. S. Taylor et al., Biomacromolecules, 19, 2351 (2018), https://doi.org/10.1021/acs.biomac.8b00517

96 J. Hombach and A. Bernkop-Schnurch, in "Handbook of Experimental Pharmacology", edited by F.B. Hofmann and M. Schafer-Korting, SpringerVerlag, Berlin, Heidelberg, vol. 197, 2010, pp. 251266

97 A. Noreen, K. M. Zia, S. Tabasum, S. Khalid and R. Shareef, Int. J. Biol. Macromol., 150, 289 (2020), https://doi.org/10.1016/j.ijbiomac.2020.01.265

98 C. Hascicek, A. Bediz-Olcer and N. Gonul, Turk. J. Pharm. Sci., 6, 177 (2009)

99 M. A. Attia, I. El-Gibaly, S. E. Shaltout and G. N. Fetih, Int. J. Pharm., 276, 11 (2004), https://doi.org/10.1016/j.ijpharm.2004.01.041

${ }^{100}$ D. Rahmat, C. Muller, J. Barthelmes, G. Shahnaz, R. Martien et al., Eur. J. Pharm. Biopharm., 83, 149 (2013), https://doi.org/10.1016/j.ejpb.2012.10.008 
${ }^{101}$ H. Okamoto, T. Nakamori, Y. Arakawa, K. Iida and K. Danjo, J. Pharm. Sci., 91, 2424 (2002)

${ }^{102}$ V. G. Kadajji and G. V. Betageri, Polymers, 3, 1972 (2011), https://doi.org/10.3390/polym3041972

103 B Sun, M. Zhang, J. Shen, Z. He, P. Fatehi et al., Curr. Med. Chem., 26, $2485 \quad$ (2019), https://doi.org/10.2174/0929867324666170705143308

104 D. N.-S. Hon, in "Polysaccharides in Medicinal Applications", edited by Severian Dumitru, Marcel Dekker, Inc., New York, 1996, pp. 87-105

105 C. L. Li, L. G. Martini, J. L. Ford and M. Roberts, J. Pharm. Pharmacol., 57, 533 (2005), https://doi.org/10.1211/0022357055957

${ }^{106}$ K. Ghosal, S. Chakrabarty and A. Nanda, Der Pharm. Sinica, 2, 152 (2011)

${ }^{107}$ M.-F. Zaltariov, B.-I. Ciubotaru, L. Vereștiuc, D. Peptanariu, D. Macocinschi et al., Cellulose Chem. Technol., $\quad 53, \quad 869 \quad$ (2019), https://doi.org/10.35812/CelluloseChemTechnol.2019. 53.84

${ }^{108}$ E. Maskova, K. Kubova, B. T. Raimi-Abraham, D. Vllasaliu, E. Vohlidalova et al., J. Control. Release, 324, 695 https://doi.org/10.1016/j.jconrel.2020.05.045

109 L. Perioli, V. Ambrogi, F. Angelici, M. Ricci, S. Giovagnoli et al., J. Control. Release, 99, 73 (2004), https://doi.org/10.1016/j.jconrel.2004.06.005

${ }^{110}$ M. Lodhi, A. Dubey, R. Narayan, P. Prabhu and S. Priya, Int. J. Pharm. Investig., 3, 47 (2013), https://doi.org/10.4103/2230-973X.108963

111 S. Salehi and S. Boddohi, Prog. Biomater., 6, 175 (2017), https://doi.org/10.1007/s40204-017-0077-7

112 C. J. Brown and A. A. Houghton, J. Soc. Chem. Ind., 60, 254 (1941)

113 Y. Sudhakar, K. Kuotsu and A. K. Bandyopadhyay, J. Control. Release, 114, 15 (2006), https://doi.org/10.1016/j.jconrel.2006.04.012

114 S. Javanbakht and A. Shaabani, Int. J. Biol. Macromol., $\quad$ 133, $21 \quad$ (2019), https://doi.org/10.1016/j.ijbiomac.2019.04.079

115 A. Fini, V. Bergamante and G. C. Ceschel, Pharmaceutics, $\quad 3, \quad 665 \quad$ (2011), https://doi.org/10.3390/pharmaceutics3040665

${ }^{116}$ F. Laffeur and A. Messirek, Ther. Deliv., 7, 63 (2016), https://doi.org/10.4155/tde.15.91

117 K. I. Draget and C. Taylor, Food Hydrocoll., 25, 251

(2011),

https://doi.org/10.1016/j.foodhyd.2009.10.007

118 M. Rinaudo, Polym. Int., 57, 397 (2008), https://doi.org/10.1002/pi.2378

${ }^{119}$ H. H. Tonnesen and J. Karlsen, Drug Dev. Ind. Pharm., 28, 621 (2002), https://doi.org/10.1081/DDC120003853

${ }^{120}$ F. Lafeur and P. Kuppers, Carbohyd. Res., 477, 51 (2019), https://doi.org/10.1016/j.carres.2019.03.009

${ }^{121}$ M. J. Martin, A. C. Calpena, F. Fernandez, M. Mallandrich, P. Galvez et al., Carbohyd. Polym., 117, 140

(2015),
${ }^{122}$ A. Bernkop-Schnurch, C. E. Kast and M. F. Richter, J. Control. Release, 71, 277 (2001), https://doi.org/10.1016/S0168-3659(01)00227-9

${ }^{123}$ R. Lutz, A. Aserin, L. Wicker and N. Garti, Food Hydrocoll., $\quad \mathbf{2 3}, \quad 786 \quad$ (2009), https://doi.org/10.1016/j.foodhyd.2008.04.009

${ }^{124}$ B. R. Thakur, R. K. Singh, A. K. Handa and M. A. Rao, Crit. Rev. Food Sci. Nutr., 37, 47 (1997), https://doi.org/10.1080/10408399709527767

${ }^{125} \mathrm{~J}$. Schmidgall and A. Hensel, Int. J. Biol. Macromol., 30, 217 (2002)

${ }^{126}$ L. Liu, M. L. Fishman, K. B. Hicks and M. Kende, Biomaterials, 26, $5907 \quad$ (2005), https://doi.org/10.1016/j.biomaterials.2005.03.005

${ }^{127}$ L. Joergensen, B. Klosgen, A. C. Simonsen, J. Borch and E. Hagesaether, Int. J. Pharm., 411, 162 (2011), https://doi.org/10.1016/j.ijpharm.2011.04.001

${ }^{128}$ R. Sharma and M. Ahuja, Carbohyd. Polym., 85, 658

(2011),

https://doi.org/10.1016/j.carbpol.2011.03.034

${ }^{129}$ Y.-H. Liao, S. A. Jones, B. Forbes, G. P. Martin and M. B. Brown, Drug Deliv., 12, 327 (2005), https://doi.org/10.1080/10717540590952555

${ }^{130}$ G. Sandri, S. Rossi, F. Ferrari, M. C. Bonferoni, N. Zerrouk et al., J. Pharm. Pharmacol., 56, 1083 (2004), https://doi.org/10.1211/0022357044085

131 A. Sosnik, J. Das Neves and B. Sarmento, Prog. Polym. Sci., 39, $2030 \quad$ (2014), https://doi.org/10.1016/j.progpolymsci.2014.07.010

${ }^{132}$ F. Laffeur, J. Wagner and J. Barthelmes, Future Med. Chem., 7, $1225 \quad$ (2015), https://doi.org/10.4155/FMC.15.66

133 J. Griesser, G. Hetenyi and A. Bernkop-Schnurch, Polymers, 10, 243 (2018), https://doi.org/10.3390/polym10030243

134 A. Jaipal, M. M. Pandey, A. Abhishek, S. Vinay and S. Y. Chard, Colloids Surf. B: Biointerfaces, 111, 644

http://dx.doi.org/10.1016/j.colsurfb.2013.06.052

${ }^{135}$ G. Singhvi, N. Hans, N. Shiva and S. K. Dubey, in "Natural Polysaccharides in Drug Delivery and Biomedical Applications", edited by M. S. Hasnain and A. K. Nayak, Elsevier Inc., 2019, pp. 121-143

${ }^{136}$ R. R. Shiledar, A. A. Tagalpallewar and C. R. Kokare, Carbohyd. Polym., 101, 1234 (2014), https://doi.org/10.1016/j.carbpol.2013.10.072

137 M. Bhatia, M. Ahuja and H. Mehta, Carbohyd. $\begin{array}{llll}\text { Polym., } & 131, & 119 & \text { (2015), }\end{array}$ https://doi.org/10.1016/j.carbpol.2015.05.049

${ }^{138}$ F. Laffeur, M. Michalek, W. Suchaoin and M. Ijaz, Ther. Deliv., 7, $423 \quad$ (2016), https://doi.org/10.4155/tde-2016-0021

${ }^{139}$ F. Laffleur and M. Michalek, Int. J. Biol. Macromol., $\quad \mathbf{1 0 2}, \quad 1250 \quad$ (2017), http://dx.doi.org/10.1016/j.ijbiomac.2017.04.123

${ }^{140}$ Y. Yuguchi, T. Thuy, H. Urakawa and K. Kajiwara, Food Hydrocoll., 16, 515 (2002), https://doi.org/10.1016/S0268-005X(01)00131-X

https://doi.org/10.1016/j.carbpol.2014.09.032 
${ }^{141}$ L. Li, R. Ni, Y. Shao and S. Mao, Carbohyd. Polym., 103, 1 http://dx.doi.org/10.1016/j.carbpol.2013.12.008

${ }^{142}$ F. Kianfar, M. D. Antonijevic, B. Z. Chowdhry and J. S. Boateng, J. Biomater. Nanobiotech., 2, 582 (2011), https://doi.org/10.4236/jbnb.2011.225070

${ }^{143}$ F. Kianfar, I. Ayensu and J. S. Boateng, Drug Dev. Ind. Pharm., 40, $361 \quad$ (2014), https://doi.org/10.3109/03639045.2012.762655

${ }^{144}$ W. Suchaoin, S. Bonengel, S. Hussain, C. W. Huck, B. N. Ma et al., J. Pharm. Sci., 104, 2523 (2015), https://doi.org/10.1002/jps.24514

${ }^{145}$ R. Hejazi and M. Amiji, in "Polymeric Biomaterials", edited by S. Dumitriu, Marcel Dekker Inc., 2002, pp. 213-237

${ }^{146}$ L. Illum, Pharm. Res., 15, 1326 (1998)

147 L. Illum and S. B. S. Davis, in "Polysaccharides: Structural Diversity and Functional Versatility", edited by S. Dumitriu, Marcel Dekker Inc., 2005, pp. 643-660 148 A. Bernkop-Schnurch and S. Dunnhaupt, Eur. J. Pharm. Biopharm., 81, $463 \quad$ (2012), http://dx.doi.org/10.1016/j.ejpb.2012.04.007

${ }^{149}$ J. Zhang, X. Zhu, Y. Jin, W. Shan and Y. Huang, Mol. Pharm., 11, $1520 \quad$ (2014), https://doi.org/10.1021/mp400685v
${ }^{150}$ D. Wu, L. Zhu, Y. Li, X. Zhang, S. Xu et al., Carbohyd. Polym., 238, $116126 \quad$ (2020), https://doi.org/10.1016/j.carbpol.2020.116126

${ }^{151}$ G. Sandri, S. Rossi, M. C. Bonferoni, F. Ferrari, Y. Zambito et al., Int. J. Pharm., 297, 146 (2005), https://doi.org/10.1016/j.ijpharm.2005.03.017

${ }^{152}$ V. Grabovac, D. Guggi and A. Bernkop-Schnurch, Adv. Drug Deliv. Rev., 57, 1713 (2005), https://doi.org/10.1016/j.addr.2005.07.006

${ }^{153}$ F. Laffleur and S. Rottges, Eur. Polym. J., 113, 60 (2019),

https://doi.org/10.1016/j.eurpolymj.2019.01.049

${ }^{154}$ C. Remunan-Lopez, A. Portero, J. L. Vila-Jato and M. J. Alonso, J. Control. Rel., 55, 143 (1998)

${ }^{155}$ A. Kumar, A. Vimal and A. Kumar, Int. J. Biol. Macromol., $\quad$ 91, 615 (2016), http://dx.doi.org/10.1016/j.ijbiomac.2016.05.054

${ }^{156}$ M. S. Freag, W. M. Saleh and O. Y. Abdallah, Carbohyd. Polym., 188, $108 \quad$ (2018), https://doi.org/10.1016/j.carbpol.2018.01.095

157 L. Mazzarino, R. Borsali and E. Lemos-Senna, $J$. Pharm. Sci., 103, $3764 \quad$ (2014), https://doi.org/10.1002/jps.24142 